\title{
EDITORIAL
}

\section{OS AVANÇOS EM CIÊNCIAS AGRÁRIAS}

Nos últimos anos a inovação possibilitou ganhos para a ciência e tecnologia, resultando em práticas modernas tanto na produção de alimentos quanto nos diagnósticos de enfermidades em plantas e nos animais. No que diz respeito à Medicina Veterinária, atualmente é possível a utilização de equipamentos de última geração para o diagnóstico por imagem à semelhança da medicina humana, como tomografia e ressonância magnética. Hoje há centros especializados para dar suporte aos clínicos veterinários, incluindo-se centros especializados em endoscopia veterinária, com possibilidade de intervenção para procedimentos complexos e cirurgias avançadas, como a endoscopia intervencionista e videocirurgias torácicas e abdominais, bem como cirurgias na área oncológica e gastroenterologia, doenças do trato reprodutivo e em nefrologia.

Aliado a esses aspectos, temos que enaltecer os profissionais dessas áreas quanto à importância no agronegócio que suporta positivamente o PIB na geração de renda para o país, que independente do modelo de seu crescimento e dos fatores associados ao seu desempenho, coloca o Brasil em destaque. Reforçam essa colocação resultados de pesquisas que utilizam indicadores que mostram o desempenho e a importância desse segmento. Importantes, ainda, as reformas positivas de politicas socioeconômicas e setoriais que formam o cenário sobre o qual as atividades produtivas organizaramse nos últimos anos. Não se deve deixar de lado que a pesquisa e o desenvolvimento explicam também o sucesso do agronegócio.

O presente número da Revista Veterinária e Zootecnia traz artigos interessantes inéditos, contribuindo com o desenvolvimento científico em diferentes áreas do conhecimento. Como artigos de revisão: Diagnóstico por Imagem de Hérnia Discal Hansen Tipo I, II e III em Cães; Estudo sobre as Diferentes Técnicas de Sexagem de Espermatozóides; Centrifugação em Gradiente de Densidade: Alternativa para Sexagem Espermática em Cães?; Sistemas de Manejo para Maximização da Eficiência Reprodutiva em Bovinos de Corte nos Trópicos; Alterações da Medula Óssea e a Importância do Mielograma no Diagnóstico da Ehrlichiose Monocítica Canina - Revisão. A revisão de literatura: Avaliação Cardiovascular do Neonato Ovino - Revisão de Literatura. Os relatos de caso: Colangite Crônica Associada à Infestação de Trematódeo por Platynosomum fastosum, Concomitante à Vesícula Biliar Dupla em um Gato - Relato de Caso; Ruptura do Tendão Pré-Púbico em Ovelha; Melanocitoma Perivulvar Congênito em Bovino; Endocardite Vegetativa em Leitões Causada por Streptococcus suis Sorotipo 9; Controle Populacional de Espécies Silvestres Invasoras por Meio de Laqueadura e Vasectomia em Primatas Callithrix penicillata: Relato de Caso. Os artigos originais: Efetividade na Reciclagem do Gel de Agarose em Laboratório Comercial; Determinação dos Valores de Colesterol-LDL de Equinos por Espectrofotometria Submetidos a Exercício em Esteira e Suplementados com Vitamina "E"; Conteúdo Lipídico, Atividade Mitocondrial e Desenvolvimento Embrionário Precoce de Oócitos Coletados de Vacas Mestiças (Bos taurus indicus); A Prática do Tratamento na Leishmaniose Visceral Canina (LVC) em Clínicas Veterinárias, Cuidados e Protocolos; Prevalência de Eimeria em Bovinos Leiteiros do Município de Silveiras - SP; Diversidade e Biomassa Fitoplanctônica em Viveiro de Carcinicultura Marinha no Estado do Pará; Caracterização da Exposição a Raiva na Colômbia, 2007-2011; Análise Ambiental, Sanitária e Econômica de um Sistema de Tratamento de Resíduos Sólidos e Efluentes em uma Granja de Suínos; Etiologia das Mastites: Pesquisa de Micro-Organismos da Classe Mollicutes; Utilização de Coleira com Imidacloprida e Flumetrina no Controle da Infestação por Pulgas em Cervos-do-Pantanal (Blastocerus Dichotomus) de Cativeiro; Etiologia, Multiresistência aos Antimicrobianos, Aspectos Epidemiológicos e Clínico- Laboratoriais de Animais Domésticos com Derrames Cavitários: Estudo Retrospectivo de 115 Casos (1997 a 2015).

Prof. Helio Langoni

Editor-Chefe 